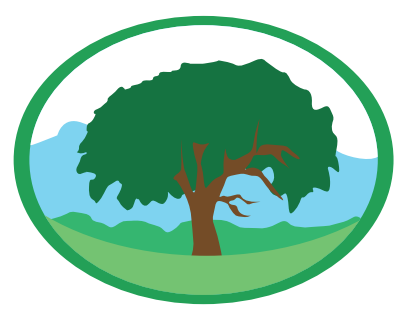

\title{
ADUBAC̣ÃO FOSFATADA NO DESENVOLVIMENTO INICIAL DE QUINOA
}

RODRIGUES, D. B.; ALMEIDA, A. S; KONZEN, L. H.; REIS, N. A.; TUNES, L. V. M.

Palavras-chave: fósforo, Resumo

Chenopodium quinoa Willd., A espécie Chenopodium quinoa Willd., é pertencente à família pseudocereal.

Chenopodiaceae, e denomina-se pseudocereal. Quanto à adubação sabe-se que a quinoa pode produzir, aproveitando-se de resíduos de outras culturas anteriormente cultivada, no entanto nota-se carência de estudos acerca da recomendação de adubação fosfatada para a espécie. Assim com o presente trabalho, objetivou-se avaliar a resposta no desenvolvimento inicial, de crescentes doses de fósforo na cultura da quinoa. 0 experimento foi conduzido com a cultivar BRS Piabiru e os tratamentos foram constituídos de diferentes doses de fósforo (cinco doses do adubo fosfatado (superfosfato triplo) 0; 50,0; 100,0; e $200,0 \mathrm{~kg} \mathrm{ha}^{-1}$ de $\mathrm{P}_{2} \mathrm{O}_{5}$ ). Após a colheita das plantas (60 dias após a semeadural o material foi destinado para avaliação quanto à massa de matéria fresca, área foliar (folha), área foliar (caule) e massa de matéria seca. Os resultados encontrados no presente estudo permitem afirmar que crescimento inicial da cultura da quinoa é afetado negativamente pela ausência do elemento fósforo. Desta forma conclui-se que doses entre 50 - $100 \mathrm{Kg} \mathrm{ha}^{-1}$ são recomendadas para à espécie em questão.

\section{PHOSPHATE FERTILIZATION IN THE EARLY DEVELOPMENT OF QUINOA}

\section{Keywords:}

Chenopodium quinod Willd, pseudocereal.

\begin{abstract}
Chenopodium quinoa Willd., belongs to the Chenopodiaceae family and is called pseudocereal. How much fertilization knows if a quinoa can produce, harness the residues of other crops previously grown, however, does not apply to studies on the recommendation of phosphate fertilization for one species. Thus, with the present work, we aimed to evaluate the response in the initial development of increasing doses of phosphorus in quinoa culture. The experiment was carried out with a cultivar BRS Piabiru which consisted of different doses of phosphorus (five doses of phosphate fertilizers (triple superphosphate) 0,50.0, 100.0, and 200.0 $\mathrm{kg} \mathrm{ha}^{-1}$ of $\mathrm{P}_{2} \mathrm{O}_{5}$ ). After harvesting the plants (60 days after sowing) or the material was destined to the evaluation of fresh matter mass, leaf area (leaf), leaf area (stem) and dry matter mass. The results found in the present study show that the initial growth of quinoa culture is negatively affected by the absence of phosphorus. Thus, it is concluded that doses between $50-100 \mathrm{Kg} \mathrm{ha}^{-1}$ are recommended for the species in question.
\end{abstract}




\section{INTRODUÇÃO}

A quinoa (Chenopodium quinoa Willd.) é uma espécie que possui potencial de fornecer elevado valor nutritivo a alimentação e destaca-se pela possibilidade de ser cultivada em terras marginais que atualmente não são adequadas para outras culturas importantes. Tal aptidão é tão relevante que foi reconhecida pelas Naçôes Unidas no ano de 2013, o qual foi o Ano Internacional da Quinoa, fazendo parte de uma das únicas três vezes em que uma planta recebeu essa designação (JARVIS et al., 2017).

Os grãos dos pseudocereais, grupo em que pertence a cultura da quinoa, são constituídos de carboidratos, lipídios, proteínas e fibras, o que também é característico nos cereais verdadeiros. Porém destacam-se pelo alto teor e qualidade de proteína, com ausência de glúten, possuindo algumas vitaminas e minerais em maior quantidade (MARADINI FILHO, 2014).

A classificação dos pseudocereais ocorre devido suas características nutricionais, quanto a composição organo-mineral (classe das dicotiledôneas) no entanto sem fazer parte a mesma família botânica (SPEHAR, 2002 e AMAYA-FARFAN, 2005).

A espécie Chenopodium quinoa é conhecida popularmente como quinoa, pertencente à família Chenopodiaceae a qual é adaptada às condiçôes de estresse hídrico, além de ser reconhecida pelo seu elevado valor nutritivo e importante papel na segurança alimentar mundial (ASSEMBLY, 2012 e SPEHAR et al., 2014).

A quinoa é uma planta anual, com ciclo variável em relação com a altitude e latitude da região de cultivo. Embora sendo originária de região de baixa latitude e alta altitude é classificada como planta de dias curtos, respondendo a mudanças na temperatura, onde o ciclo da cultura é determinado pela relação entre temperatura/fotoperíodo seu ciclo varia de 80 a 150 dias e a estatura das plantas chega à média $1,90 \mathrm{~m}$ de altura (SPEHAR; SANTOS, 2002).

A diferenciação floral acontece 30 dias após a emergência, e após 45 dias ocorre à antese. Com sistema radicular pivotante, vigoroso e profundo, pode alcançar $1,80 \mathrm{~m}$, bastante ramificado e fibroso, conferindo resistência a seca e estabilidade da planta (MORAES, 2013).
Quanto à adubação sabe-se que a quinoa pode produzir, aproveitando- se de resíduos de outras culturas anteriormente cultivada, apesar disso, quando se adiciona outros nutrientes principalmente NPK, nota-se um expressivo incremento de rendimento tornando a correção do solo tanto em calagem quanto em adubação compensatória para o cultivo, no entanto se faz necessárias pesquisas que elucidem a responsividade da cultura com relação às doses a serem disponibilizadas destes elementos (SPEHAR, 2007).

A quinoa possui também um potencial de ciclagem de nutrientes constituindo a renovação do solo e de matéria orgânica. Há relatos na bibliografia a recomendação do cultivo da quinoa em sequência à cultura da soja ou milho, sendo que neste caso é sugerido como adubação de base quantidades entre 60 e $100 \mathrm{Kg} \mathrm{ha}^{-1}$ de $\mathrm{P}_{2} \mathrm{O}_{5}$ e $\mathrm{K}_{2} \mathrm{O}$, a aplicação de nitrogênio é recomendada na quantidade de $60 \mathrm{Kg} \mathrm{ha}^{-1}$, devendo ser parcelado (metade deve ser disponibilizado na semeadura e o restante aos 45 dias após a emergência) (SPEHAR, 2007). Contudo os solos da região sul do Rio Grande do Sul são, à semelhança dos demais solos do Brasil, carentes de fósforo (MACHADO, 1992).

O fósforo é um elemento primordial a divisão celular, interferindo no crescimento da parte aérea e sistema radicular, bem como na reprodução e no metabolismo vegetal em várias rotas metabólicas como a fotossíntese, respiração e síntese de compostos. O déficit de fósforo no solo acarreta a diminuição do crescimento das plantas e o potencial de rendimento nos estádios vegetativos e reprodutivos das plantas, podendo inclusive promover aborto de flores e decréscimo da produção (VITTI e TREVISAN, 2000).

A baixa disponibilidade de fósforo $(\mathrm{P})$ para as plantas cultivadas é uma característica predominante dos solos brasileiros em função da sua grande adsorção à fase mineral, predominantemente de baixa reversibilidade, principalmente nos óxidos de $\mathrm{Fe}$ e $\mathrm{Al}$, sendo necessária a inclusão desse nutriente por meio da aplicação de fertilizantes fosfatados (SCHONINGER et al., 2013).

O cultivo da quinoa é originariamente caracterizado por sistema produtivo familiar, ou seja, cultivo em pequenas propriedades e recentemente vem se expandido em termos de área cultivada especialmente 
com o intuito da produção de sementes da espécie. E acredita-se, em função de relatos na bibliografia atualmente disponível, que a adubação é realizada basicamente pelo incremento de esterco de animais cultivados nas propriedades. A exemplo disso está à utilização de esterco bovino no Planalto Sul Boliviano, o qual a priori beneficia significativamente as condiçóes físicas do solo (HUANCA, 2008).

Diante das diversas razóes que fazem a cultura da quinoa promissora e importante a expansão agrícola alternativa e a qualidade da alimentação humana faz-se imprescindível o conhecimento acerca das condiçóes ideias para o alcance do potencial de produção, assim sendo, com o presente trabalho, objetivou-se avaliar a resposta no desenvolvimento inicial, de crescentes doses de fósforo na cultura da quinoa.

\section{MATERIAL E MÉTODOS}

O experimento foi realizado no Campus da Universidade Federal de Pelotas, município Capão do Leão - RS (coordenadas aproximadas de 31 $52^{\circ} \mathrm{S}$ e 52० 21'W; altitude de $13 \mathrm{~m}$ ), no período de $01 \mathrm{de}$ outubro de 2015 a 20 de novembro de 2015 .

$\mathrm{O}$ ensaio foi conduzido em uma estufa modelo "Arco Pampeana", disposta no sentido Norte-Sul, revestida com filme de polietileno de baixa densidade (150 $\mu \mathrm{m}$ de espessura), compreendendo uma área de $210 \mathrm{~m}^{2}(10 \times 21 \mathrm{~m})$.

O experimento foi realizado com a cultura da quinoa (BRS Piabiru) com 98\% de germinação e 93\% de vigor (conforme teste de emergência a campo: realizado com 4 repetiçóes de 100 sementes e contabilizados aos 13 dias após a semeadura, momento em que a emergência estabilizou), para a avaliação da qualidade inicial das sementes foram realizados os seguintes testes:

Germinação: foram utilizadas quatro repetiçôes com quatro subamostras de 50 sementes para cada tratamento. As sementes foram semeadas em papel mata borrão, umedecido com água destilada, na proporção de 2,5 vezes a massa do papel seco e mantido em germinador regulado a $25^{\circ} \mathrm{C}$. As contagens foram realizadas no quarto e sexto dia após a montagem e os resultados expressos em porcentagem.

Emergência: utilizaram-se quatro repetiçôes de 50 sementes distribuídas em células individuais de bandejas, contendo solo. As bandejas foram mantidas em casa de vegetação e a avaliação foi realizada no décimo terceiro dia após a semeadura, momento em que houve a estabilização da emergência. Os resultados foram expressos em percentagem de plântulas emergidas (BORGES, 2017).

Os tratamentos foram constituídos de diferentes doses de fósforo (cinco doses do adubo fosfatado (superfosfato triplo) 0; 50,0; 100,0 e 10,0 kg ha-1 de $\mathrm{P}_{2} \mathrm{O}_{5}$ ). Estas foram estimadas, utilizados vasos com capacidade de 4L, preenchidos com Planossolo típico da região, e a semeadura realizada a $3 \mathrm{~cm}$ de profundidade (RODRIGUES, 2018). O delineamento experimental utilizado foi em blocos ao acaso.

Foi realizado o desbaste aos 30 dias após a semeadura deixando-se oito plantas por vaso, e estes foram irrigados manualmente a cada dois dias. A análise foliar e massa seca foram realizadas aos 60 dias após a semeadura, momento em que as plantas se encontravam em tamanho suficiente para as avaliaçóes. Após a colheita das plantas (em sua totalidade) de cada vaso devidamente identificado o material foi destinado para avaliação quanto à massa de matéria fresca, área foliar (folha), área foliar (caule) e massa de matéria seca.

Área foliar: para esta avaliação foi utilizado um determinador de área foliar Licor LI2600 do Laboratório Didático de Análise de Sementes da Universidade Federal de Pelotas, o qual forneceu leitura direta em centímetros quadrados $\left(\mathrm{cm}^{2}\right)$.

Massa de matéria fresca e seca: com o auxílio de uma balança de precisão as amostras (plantas de cada balde) tiveram sua massa fresca determinada e foram encaminhadas à estufa de renovação/circulação de ar forçada, à temperatura de $65^{\circ} \mathrm{C}$, até atingir peso constante.

Os dados obtidos foram submetidos à análise de variância e a comparação de médias foi realizada pelo teste de Tukey a $5 \%$ de probabilidade, usando o software estatístico Assistat ${ }^{\oplus}$ (versão 7.7 beta).

\section{RESULTADOS E DISCUSSÃO}

No que diz respeito à avaliação das variáveis matéria fresca, área foliar, e massa de matéria seca da cultura da quinoa em funçáo dos tratamentos, a Figura 1 mostra 
que mesmo embora não haja diferença significativa é possível observar o aumento crescente dos resultados
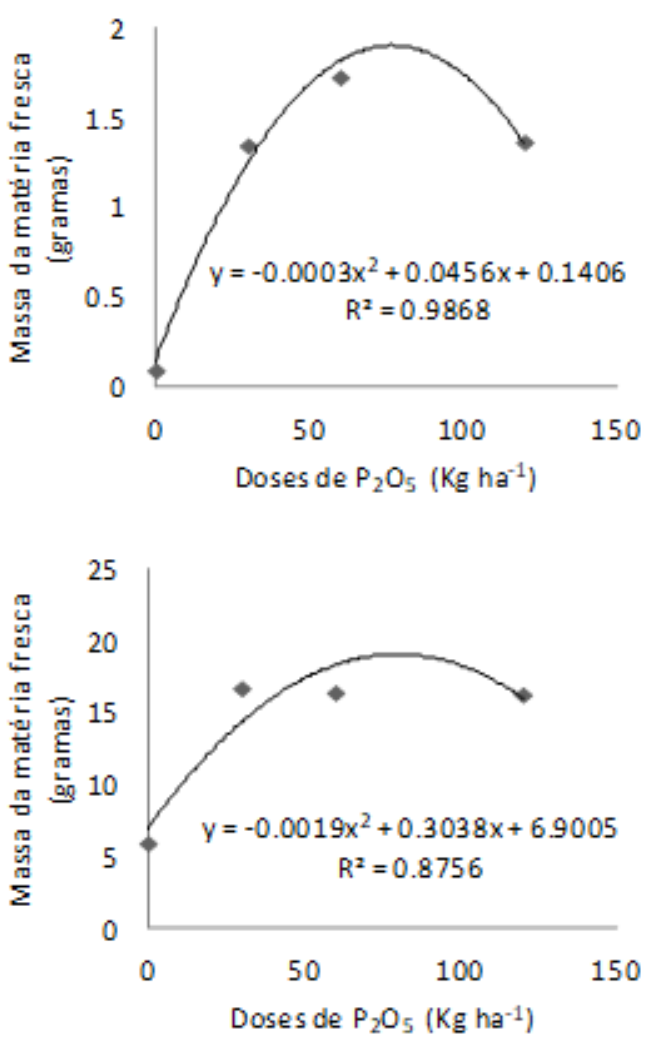

das variáveis analisadas até a dose $60 \mathrm{~kg}$ ha-1, ocorrendo redução dos valores nas doses mais altas, a partir desta.
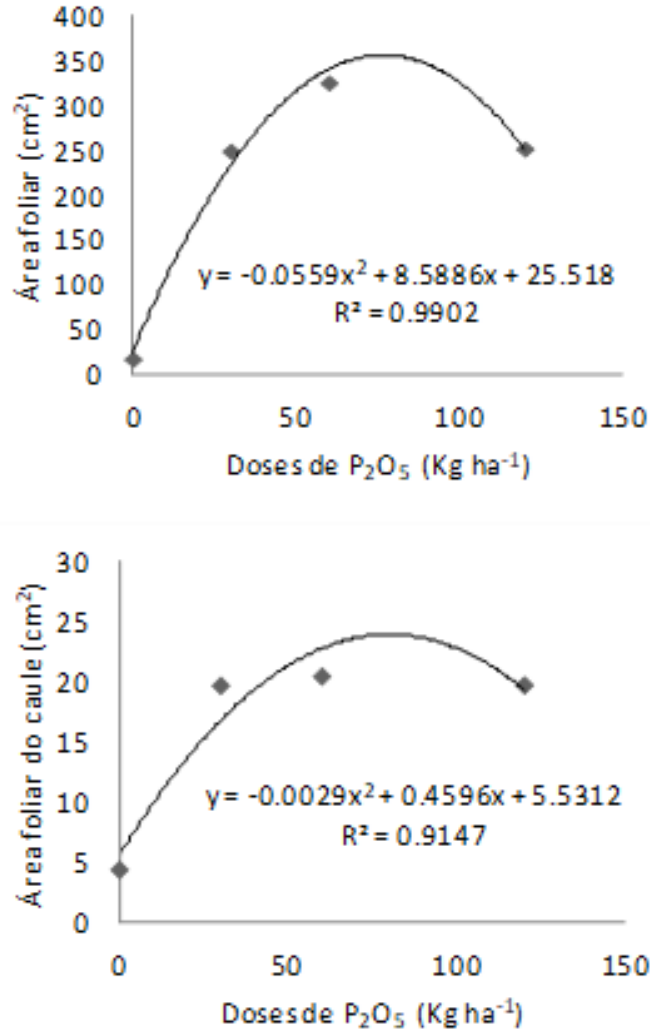

Figura 1. Massa da matéria fresca (g), massa da matéria seca (g), área foliar do caule $(\mathrm{cm} 2)$ e área foliar (c) em função das doses de fósforo $10 \mathrm{~g}$. balde 4 litros-1; $9 \mathrm{~g}$.balde 4 litros-1; 13,5g.balde 4 litros-1 e 18g.balde 4 litros-1 respectivamentel no desenvolvimento inicial da cultura da quinoa. Capão do Leão-RS.

A massa da matéria seca é uma das variáveis mais importantes para avaliação da influência da adubação no crescimento e desenvolvimento das plantas, contudo vale ressaltar que o conhecimento do efeito dos tratamentos sobre a área foliar é de grande relevância, já que existe uma relação bastante afim entre a área foliar e a atividade fotossintética, e, por conseguinte maior desenvolvimento das plantas (OLIVEIRA et al., 2006).

Observa-se (Figura 1) que o ajuste a tendência quadrática para todas as variáveis avaliadas assemelhamse com os resultados encontrados por Saldanha et al. (2018) com a cultura do milho, além disso é possível verificar a semelhança dos resultados, entre as doses 50 e $100 \mathrm{~kg}$. ha-1 de $\mathrm{P}_{2} \mathrm{O}_{5}$, desta forma pode-se dizer que a cultura da quinoa possui requerimento análogo a esta gramínea quando relacionado a adubaçáo fosfatada.

No Brasil, estudos sobre os níveis de adubação da cultura que permitem atender as exigências para alcançar rendimento econômico, são insuficientes. A capacidade produtiva é em média é de 3,0 t ha ${ }^{-1}$ de grãos e quase 7,0 t ha ${ }^{-1}$ de matéria seca, e segundo Carbone-Risi (1986) na Inglaterra chegou a 6 t ha 1. Ressaltando que o fósforo tem relevância no que tange a produtividade de plantas, pois faz parte da constituição das membranas celulares (fosfolipídeos), dos ácidos nucleicos e como também no conteúdo de compostos armazenadores de energia, como ATP (trifosfato de adenosina) a molécula mais importante destes compostos. Tal energia é aproveitada nos processos de germinação, fotossíntese, absorção ativa dos nutrientes do solo e síntese de vários compostos orgânicos, como carboidratos, proteínas e lipídeos (TANAKA et al., 1993).

Embora a exiguidade de informaçóes a respeito da disponibilidade de fósforo as plantas e a influência em diversas espécies de forma geral, há alguns autores que recomendam o elemento em níveis a cima dos valores indicados, em campos de produção de sementes, por afetar de forma significativamente positiva o atributo 
da qualidade fisiológica da semente (CORRÊA et al., 2004; MARCOS-FILHO, 2015; PESKE et al., 2009).

Toledo e Marcos Filho (1977) destacam que as recomendações de adubação ressaltam o efeito sobre a produtividade, contudo sem relacionar a qualidade das sementes, todavia, a produção e qualidade da semente são influenciadas pela disponibilidade de nutrientes à lavoura, por afetar a formação do embrião e dos órgãos de reserva, do mesmo que a composição química e, consequentemente, o metabolismo e o vigor (CARVALHO e NAKAGAWA, 2012).

A suplementação com o elemento $\mathrm{P}$ (fósforo) é determinante no desenvolvimento inicial das plantas, mesmo embora nos estádios iniciais do desenvolvimento seja basicamente dependente das reservas da semente. A falta de P no início do desenvolvimento restringe o crescimento posterior, consequentemente interferindo o completo crescimento e alcance do rendimento potencial da espécie (GRANT, 2001 e SILVA et al., 2018).

Analisando de forma ampla os resultados encontrados com esta pesquisa é possível constatar que o ponto mínimo e máximo de eficiência da disponibilizaçáo do elemento fica entre 50 e $100 \mathrm{Kg}$. $\mathrm{ha}^{-1}$ respectivamente, ressaltando que a tomada de decisão deste critério leva em consideração o mínimo custo monetário possível ao cultivo, desta forma recomenda-se a dose mínima suficiente para o alcance do máximo potencial.

\section{CONCLUSÃO}

1- Os resultados encontrados no presente estudo permitem afirmar que crescimento inicial da cultura da quinoa é afetado negativamente pela ausência do elemento fósforo. Desta forma conclui-se que doses entre 50 - $100 \mathrm{Kg} \mathrm{ha}^{-1}$ são recomendadas para à espécie em questão.

\section{LITERATURA CITADA}

AMAYA-FARFAN, J.; MARCÍLIO, R.; SPEHAR, C. R. Deveria o Brasil investir em novos grãos para sua alimentação? A proposta do amaranto (Amaranthus sp.). Segurança Alimentar e Nutricional, v.12, p.4756, 2005. https://doi.org/10.20396/san.v12i1.1838.
ASSEMBLY, UN GENERAL. The Future we want (Resolution adopted by the General Assembly on 27 July 2012). The United Nations, v. 53, p. 45, 2012.

BORGES, Carolina Terra. Desenvolvimento de metodologias para avaliaçáo da qualidade fisiológica e conservaçáo de sementes de quinoa (Chenopodium quinoa Willd.). 2017. 81f. Tese (Doutorado) - Faculdade de Agronomia Eliseu Maciel, Universidade Federal de Pelotas, Pelotas, 2017.

CARBONE-RISI, J. J. M. Adaptation of the Andean grain crop quinoa for cultivation in Britain. 1986. 123 f. Tese (Doutorado) - University of Cambridge, Cambridge.

CARDOSO DE MORAES FILHO, Luiz Felipe. Quinoa (Chenopodium quinoa Willd.) uma Revisão Bibliográfica. 2013. 51 f. Dissertação (Bacharelado em Engenharia Agronômica) - Curso de Engenharia Agronômica, Faculdade de Agronomia e Medicina Veterinária - FAV, Universidade de Brasília, Brasília. 2013.

CARVALHO, N. M.; NAKAGAWA, J. Sementes: ciência, tecnologia e produçáo. 5.ed. Jaboticabal: FUNEP, 2012. 590p.

CORREAA, J. C.; MAUAD, M.; ROSOLEM, C. A. Fósforo no solo e desenvolvimento de soja influenciados pela adubação fosfatada e cobertura vegetal. Pesquisa Agropecuária Brasileira, v.39, n.12, p.1231-1237, 2004. http://dx.doi.org/10.1590/ S0100-204X2004001200010.

GRANT, C.A; FLATEN, D.N; TOMASIEWICZ, D.J; S.C. SHEPPARD, D.J.C. A importância do fósforo no desenvolvimento inicial da planta. Informaçôes agronômicas no 95 - setembro/2001.

HUANCA, R. A.. Evaluación de diferentes niveles de abono orgânico y Riego deficitário sobre el desarrolho y rendimiento de quinoa (Chenopodium quinoa Willd) em el Planalto Central. 2008. $147 \mathrm{f}$. Tese de licenciatura - Universidad Mayor de San 
Andrés. La Paz - Bolivia.

JARVIS, D. E., HO, Y. S., LIGHTFOOT, D. J., SCHMÖCKEL, S. M., LI, B., BORM, T. J. \& KHARBATIA, N. M. The genome of Chenopodium quinoa. Nature, v. 542, n. 7641, p. 307, 2017.

MACHADO, M. I. C. S. O fósforo nos solos da regiáo sul do Rio Grande do Sul - formas, capacidade máxima de adsorçáo, poder tampáo recomendação de adubaçáo. Pelotas, 1992, 116f. Dissertação (Mestrado em Agronomia - Solos) -Faculdade de Agronomia Eliseu Maciel, Universidade Federal de Pelotas.

MARADINI FILHO, A. M. Caracterização físicoquímica, nutricional e fatores antinutricionais de quinoa da variedade brasileira BRS Piabiru. 2014. 202 f. Tese (Doutorado em Ciência e Tecnologia de Alimentos) - Universidade Federal de Viçosa, Viçosa. 2014.

MARCOS FILHO, J. Fisiologia de sementes de plantas cultivadas. Ed? Londrina: ABRATES, 2015. $659 \mathrm{p}$.

OLIVEIRA, M. K. T.; OLIVEIRA, F. A., MEDEIROS, J. F.; LIMA, C. J. G. S.; GUIMARÁES. Efeito de diferentes teores de esterco bovino e níveis de salinidade no crescimento inicial da mamoneira (Ricinus communis L.). Revista Verde de Agroecologia e Desenvolvimento Sustentável, v.1, n.1, p.68-74, 2006.

PESKE, F. B.; BAUDET, L.; PESKE, S. T. Produtividade de plantas de soja provenientes de sementes tratadas com fósforo. Revista Brasileira de Sementes, v.31, n. 1, 2009. http://dx.doi.org/10.1590/ S0101-31222009000100011.

RODRIGUES, Daniele Brandstetter. Caracterizaçáo, qualidade fisiológica e produçáo de sementes de Quinoa no sul do Rio Grande do Sul. 2018. 71f. Tese (Doutorado) - Faculdade de Agronomia Eliseu Maciel, Universidade Federal de Pelotas, Pelotas, 2018.
SALDANHA, E. C. M., DA ROCHA, M. E. L., DE ARAÚJO, J. L. S., ALVES, J. D. N., DE CINQUE MARIANO, D., \& OKUMURA, R. S. Adubação fosfatada na cultura do milho no nordeste paraense. Revista de Ciências Agroveterinárias, v. 16, n. (4), p. 441-448, 2018.

SCHONINGER, E. L.; GATIBONI, L. C.; ERNANI, P. R. Fertilização com fosfato natural e cinética de absorção de fósforo de soja e plantas de cobertura do cerrado. Semina: Ciências Agrárias, v.34, n.1, p.95-106, 2013. http://dx.doi.org/10.5433/1679$0359.2013 \mathrm{v} 34 \mathrm{n} 1 \mathrm{p} 95$.

SILVA, J., MAZON, A., MACHADO, J., ALMEIDA, A., \& GONÇALVES, V. Desenvolvimento de plantas de soja submetidas a diferentes doses de fósforo aplicadas ao solo. Revista da Jornada de PósGraduaçáo e Pesquisa-Congrega Urcamp, p. $1067-$ 1076, 2018.

SPEHAR, C. 2002. Utilização da quinoa como alternativa para diversificar alimentos. In: SIMPÓSIO SOBRE INGREDIENTES NA ALIMENTAÇÃO ANIMAL, 2., 2002, Uberlândia. Anais... Uberlândia, MG: Colégio Brasileiro de Nutrição Animal: UFU, p. 4958.

SPEHAR, C. R.; ROCHA, J. E. da S.; RIBEIRO JÚNIOR, W. Q.; SANTOS, R. L. de B.; ASCHERI, J. L. R.; SOUZA, F. F. de J. Avances y desafíos de la producción y utilización de la quinua en Brasil. In: BAZILE, D. (Coord.). Estado del arte de la quinua en el mundo en 2013. Santiago: FAO, 2014. p.681- 706.

SPEHAR, C. R.; SANTOS, R. L. B. Quinoa BRS Piabiru: alternativa para diversificar os sistemas de produção de grãos. Pesquisa Agropecuária Brasileira, Brasília, DF, v. 37, n. 6, p. 889-893, 2002.

SPEHAR, C. R.; SANTOS, R. L. B.; VELOSO, R. F; CARVALHO, W. P.; ANDRADE, S. C. Quinoa: alternativa para a diversificação agrícola e alimentar. Planaltina, DF: Embrapa Cerrados, 2007. 103p. 
TANAKA, R. J. Nutrição mineral da soja. In: ARANTES, N. E.; SOUZA, P. I. M. (Ed). Cultura da soja nos cerrados. Piracicaba: Potafos, 1993.

TOLEDO, F. F.; MARCOS FILHO, João. Manual das Sementes: tecnologia da produção. São Paulo: Agronômica Ceres, 1977. 224p.

VITTI, G. C.; TREVISAN, W. Manejo de macro e micronutrientes para alta produtividade da soja. Informaçóes Agronômicas, n.90, p.1-16, 2000. 